\title{
Notas sobre Ugni Turcz. (Myrtaceae) na Amazônia Brasileira
}

\author{
Alessandro Silva do ROSÁRIOํㅜ, Ricardo de S. SECCO² ${ }^{2}$ João Batista Fernandes da SILVA ${ }^{3}$
}

\begin{abstract}
RESUMO
O objetivo deste trabalho é registrar a ocorrência de Ugni Turcz., um gênero raro e mal conhecido na Amazônia Brasileira. Ugni é composto por quatro espécies, sendo que apenas Ugni myricoides (Kunth) O. Berg ocorre no Brasil, habitando principalmente regiões de altitude nos Estados de Roraima e Amazonas (Serra da Neblina), sendo conhecido nos Herbários regionais somente de uma coleta. Ugni têm sido considerado por muitos botânicos como sinônimo de Myrtus Linnaeus, devido ambos apresentarem caracteres morfológicos muito semelhantes entre si. Porém, Ugni é caracterizado por apresentar hábito arbóreo ou arbustivo, folhas pequenas, freqüentemente com $2 \mathrm{~cm}$ de comprimento ou menos, coriáceas, margens revolutas, venação secundária inconspícua, inflorescências unifloras, corola (4) 5-mera, pétalas brancas, com mancha avermelhada no centro, estames 25-30, anteras sagitadas, ovário (2-) 3-locular, 4-23 óvulos por lóculo, sementes 15-20 e embrião em forma de C.
\end{abstract}

PALAVRAS-CHAVE

Ugni, Myrtaceae, taxonomia, Serra da Neblina, Amazônia.

\section{Notes on the genus Ugni Turcz. (Myrtaceae) in the Brazilian Amazonia.}

\begin{abstract}
The goal of this study is to document the occurrence of the genus Ugni Turcz. in Brazil, where it is rare and poorly known. Ugni comprises four species, but only U. myricoides (Kunth) O. Berg occurs in Brazil, in high-elevation areas on the Roraima Mountain (State of Roraima) and in the Serra of Neblina (State of Amazonas). This species is only known in the Amazonian herbaria in just one collection. Ugni is easily confused with Myrtus L. due to the morphological resemblance between them, but Ugni are shrubs or small trees. Its leaves are small, usually less than $2 \mathrm{~cm}$ long, and coriaceous, and have revolute margins and inconspicuous secondary veins; its flowers are solitary and usually bave five, sometimes four, white petals with a reddish central spot and usually three, sometimes two, locules per ovary, each with four to 23 ovules; and its fruits have 15 to 20 seeds with C-shaped embryos.
\end{abstract}

\section{KEY WORDS}

Ugni, Myrtaceae, taxonomy, Serra of Neblina, Amazonia.

Segundo Landrum \& Kawasaki (1997) Ugni é composto por quatro espécies, sendo que apenas Ugni myricoides (Kunth) O. Berg ocorre no Brasil, habitando principalmente regiões de altitude em Roraima e Serra da Neblina. Berg apud McVaugh (1958) afirma que o gênero pode apresentar até 10 espécies (número este também registrado em TROPICOS-www.mobot.org), concentrando-se especialmente no Sul do México e Chile. McVaugh (1969) relata que U. myricoides apresenta variações infra-especificas, conforme chave de identificação por ele proposta.
O objetivo do presente trabalho é registrar a ocorrência de Ugni, um gênero raro e mal conhecido na Amazônia Brasileira, ao mesmo tempo contribuindo para o conhecimento das Myrtaceae da região.

Ugni Turcz., Bull. Soc. Imp. Naturalistes Moscou 21(1): 579. 1848.

Arbustos 1-2 $\mathrm{m}$ ou árvores $5 \mathrm{~m}$ de alt. Folhas pequenas, freqüentemente $2 \mathrm{~cm}$ compr. ou menos, coriáceas, margens

\footnotetext{
${ }^{1}$ Bolsista GM/CNPq/Museu Paraense Emílio Goeldi. e-mail: asrosario@museu-goeldi.br

${ }^{2}$ Pesquisador MCT/Museu Paraense Emílio Goeldi. e-mail: rsecco@museu-goeldi.br

${ }^{3}$ Bolsista CNPq/Museu Paraense Emílio Goeldi
} 


\section{ACTA AMAZONICA}

NOTAS SOBRE UGNI TURCZ. (MYRTACEAE)

NA AMAZÔNIA BRASILEIRA revolutas, venação secundária inconspícua. Inflorescências unifloras; corola (4) 5-mera, pétalas brancas, com mancha avermelhada no centro; estames 10 ou mais (25 ou mais, segundo McVaugh, 1958), anteras sagitadas; ovário (2-) 3-locular; 4-23 óvulos por lóculo; sementes 15-20; embrião em forma de C.

Ugni têm sido considerado por muitos botânicos como um sinônimo de Myrtus Linnaeus, devido ambos apresentarem caracteres morfológicos muito semelhantes entre si, causando assim, confusão em suas delimitações taxonômicas. Ainda que um conjunto de características, aliadas à distribuição geográfica, os aproximem, Ugni se destaca por apresentar um número reduzido de estames (10-15) e anteras sagitadas.

Landrum apud Holst et al. (2003) considera quatro das oito formas e variedades de Ugni myricoides, descritas por McVaugh (1969), como sinônimos de $U$. myricoides

O táxon, objeto deste estudo, enquadra-se perfeitamente em Ugni myricoides var. myricoides, segundo o conceito de McVaugh (1969). Porém, considerando-se que no presente estudo não foi possível consultar material dos táxons infra-específicos de $U$. myricoides, apresenta-se aqui uma descrição da espécie em sentido amplo, sem aludir às variedades e formas descritas e/ou aceitas por McVaugh (1969). Para maiores esclarecimentos sobre sinônimos propostos para Ugni myricoides, os autores sugerem consulta à base de dados TROPICOS (www.mobot.org) e Landrum apud Holst et al. (2003).

Ugni myricoides (Kunth) O. Berg, Linnaea 27: 391. 1856. (Figura 1)

Myrtus myricoides Kunth, in Humboldt et al., Nov. Gen \& Sp. 6: 131 (folio ed. p. 104). pl. 539. 1823. Tipo. Humboldt E Bonpland 3515, no date, Peru (P).

Subarbusto $15 \mathrm{~cm}$ alt. Ramos estriados, rugosos, glabrescentes. Folhas decussadas, 4-11 mm compr., 2-6 mm larg., peninérveas, elípticas a elíptico-oblongas, cartáceas, glabras na face adaxial, glabrescentes na abaxial; glândulas translúcidas em forma de pontos escuros evidentes apenas na face abaxial; nervuras laterais finíssimas, invisíveis sob lupa, a mediana levemente impressa na face adaxial, proeminente na abaxial; tricomas simples; margens levemente revolutas; ápice levemente agudo, base variando desde cuneada à obtusa; pecíolo 1-2 mm de compr., glabro, ou com tricomas simples, esparsos. Inflorescências em racemos axilares. Botões florais fendidos, ca. de $5 \mathrm{~mm}$ compr. Flores andróginas, freqüentemente solitárias; tricomas simples, esparsos externamente; pedicelos glabrescentes, rugosos, 4-9 $\mathrm{mm}$ de compr.; brácteas basais aos pares, lineares, 3,5-4 mm compr., sépalas 4 , lanceoladas, glabras, semelhantes às brácteas; pétalas 4 , ovais, $5 \mathrm{~mm}$ compr. ou mais, $4 \mathrm{~mm}$ larg., glabras; estames em número reduzido (ca. de 10-15), ca. 2 mm compr.; anteras sagitadas; ovário ovóide, 3-locular, glabro; estilete 1, $4 \mathrm{~mm}$ compr., glabro; hipanto longo, ca. 3,5 mm compr. Fruto baga, 3-4 mm diâm., glabro, rugoso, corola e estames persistentes, sementes 14-20, placentação axial.
Distribuição geográfica (Figura 2). Sul do México, América Central, Colômbia, Venezuela, Guiana, Equador, Peru, Brasil (Amazonas: Serra da Neblina; Roraima: Monte Roraima).

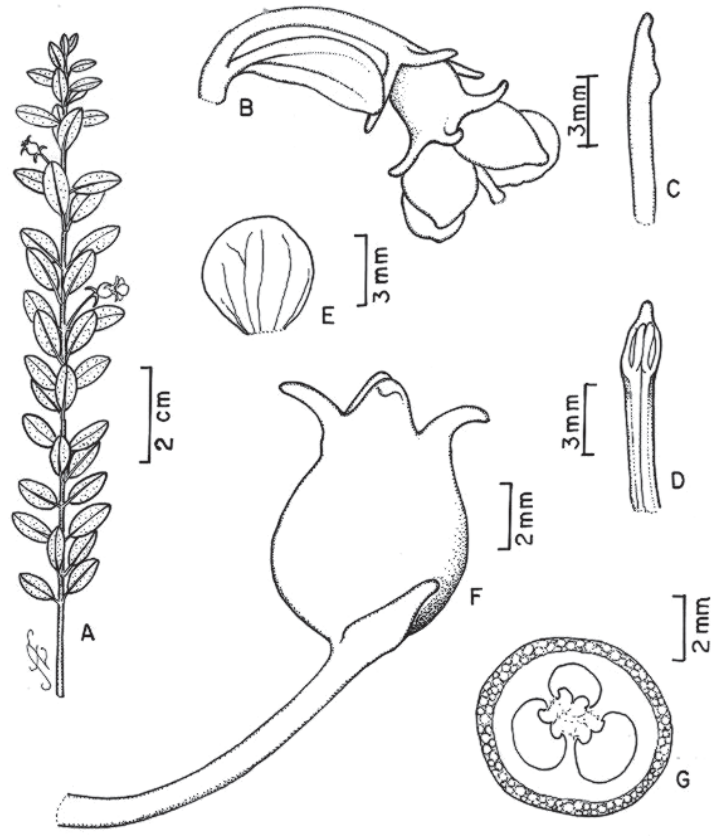

Figura 1 - Ugni myricoides (Kunth) O. Berg: A, ramo fértil; B, flor em vista lateral; $C$, estame com antera sagitada em vista lateral; $D$, estame com antera sagitada em vista frontal; E, pétala; $F$, fruto; $G$, corte transversal do ovário. (Baseada em J. B. F. da Silva 1153).

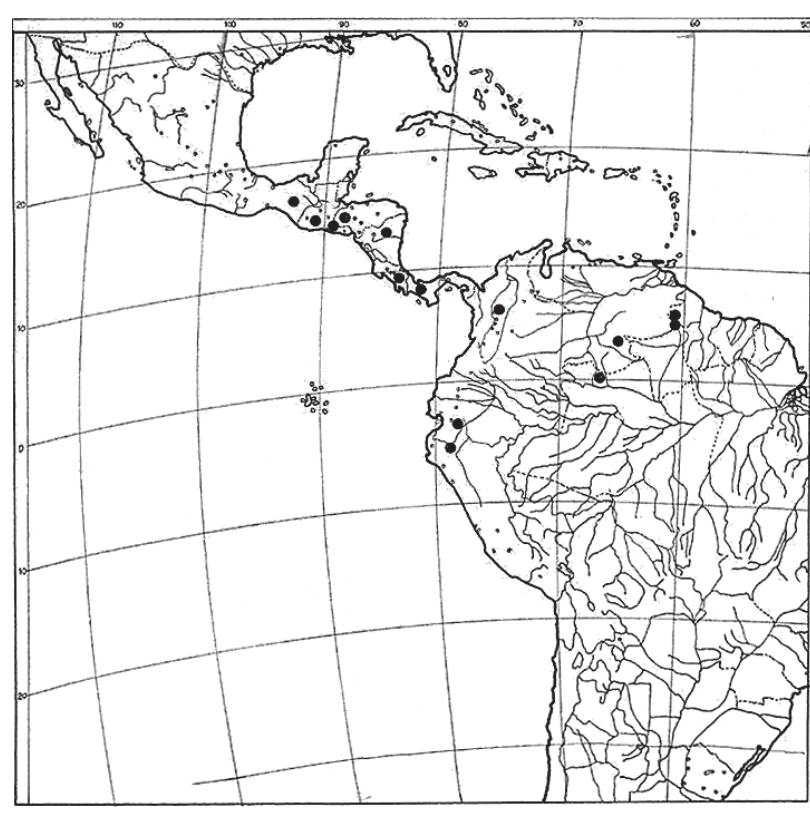

Figura 2 - Distribuição geográfica conhecida de Ugni myricoides (Kunth) O. Berg. 


\section{ACTA AMAZONICA}

NOTAS SOBRE UGNI TURCZ. (MYRTACEAE)

NA AMAZÔNIA BRASILEIRA
Esta espécie é caracterizada principalmente por apresentar folhas curtas (4-11 mm de comprimento) e estreitas (2-6 $\mathrm{mm}$ de largura), nervuras inconspícuas, destacando-se apenas a nervura central, as margens levemente revolutas, as flores com poucos estames (ca. de 10-15), opondo-se ao padrão das Myrtaceae e corola tetrâmera, lembrando a forma de um calículo.

Não existem registros de Ugni myricoides nos Herbários IAN e INPA, sendo este o primeiro registro no $M G$, o que reforça a raridade desse gênero na região.

Material examinado. Brasil. Amazonas: Sta. Izabel do Rio Negro, Serra da Neblina, 29.08.2002 (fl. \& fr.), J.B.F. $d a$ Silva 1153 (MG).

\section{AGRADECIMENTO}

Ao Antônio Elielson S. Rocha, bolsista CNPq/DCR, pela colaboração na identificação e ilustração do material coletado.

\section{BIBLIOGRAFIA CITADA}

Holst, B.K., Landrum, L.; Grifo, F. 2003. Myrtaceae. In: Steyermark, J. A et al. (eds.). Flora of the Venezuelan Guayana 7:1-99.

Landrum, L. R.; Kawasaki, M. L. 1997. The Genera of Myrtacae in Brazil: an illustrated synoptic treatment and identification keys. Brittonia 49: 508 - 536.

McVaugh. R. 1958. Flora of Peru: Myrtaceae. Botanical Series Field Museum of Natural History 13(2): 569-819.

McVaugh, R. 1969. Myrtaceae. In: Maguire, B. and coll., The Botany of the Guayana Highland. Part VIII. Memoirs of The New York Botanical Garden 18: 55 - 286.

RECEBIDO EM 18/06/2003

ACEITO EM 19/01/2004 
